Received: 25 January 2017

Accepted: 22 January 2018

Published online: 02 February 2018

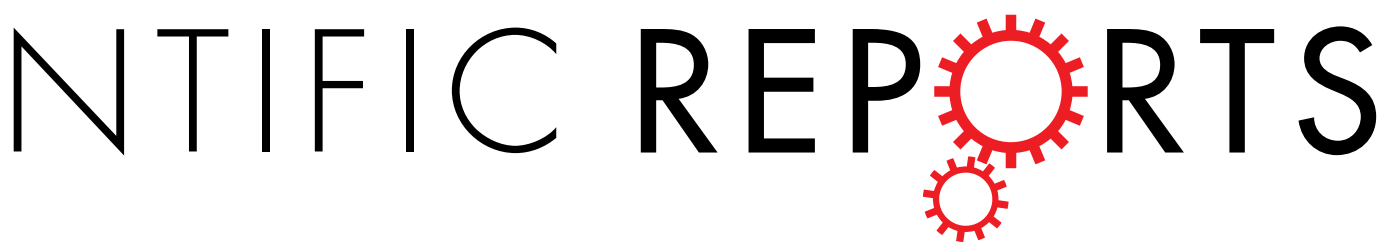

\title{
Comparing the Intramedullary Nail and Extramedullary Fixation in Treatment of Unstable
} Intertrochanteric Fractures

\author{
Wen-Qiang Zhang ${ }^{1}$, Jian Sun ${ }^{2}$, Chun-Yu Liu ${ }^{1}$, Hong-Yao Zhao ${ }^{1}$ \& Yi-Feng Sun ${ }^{1}$
}

Treatment options for unstable intertrochanteric fractures include intramedullary nail and extramedullary fixation, although evidence regarding the most appropriate treatment for such fractures remains controversial. Our hypothesis was that there would be no obvious differences in mortality rates, functional outcomes and complications between the two groups. We therefore conducted a meta-analysis to compare the relative advantages of intramedullary nail and extramedullary fixation. A total of 10 randomized controlled trials including only patients with unstable intertrochanteric fractures were included in the final analysis. We found that no statistically significant difference in one-year mortality was observed between the two groups (RR: $0.78,95 \% \mathrm{Cl}: 0.55-1.10$, $\mathrm{p}=0.160$ ). Analysis of exact $p$ values from five included studies indicated that functional outcomes were markedly better for patients of the intramedullary nail group when compared with those of the extramedullary fixation group $(p=0.0028)$, although evidence remains controversial. Higher incidences of all complications were noted for extramedullary fixation (RR:1.48, 95\% Cl: 1.12-1.96, $p=0.006$ ). However, no significant differences in implant-related complications were observed between the two groups (RR:1.20, 95\% Cl: $0.73-1.97, p=0.475$ ). Therefore, comparing with extramedullary fixation, the intramedullary nail method would be more reliable and should be encouraging for unstable intertrochanteric fractures.

Intertrochanteric hip fractures have become increasingly common, most frequently occurring in older adults. Between 35-40\% of these fractures are classified as unstable (AO/ASIF classification: 31-A2/31-A3) and are thus associated with high rates of morbidity and mortality ${ }^{1}$. Management of unstable intertrochanteric fractures remains challenging, particularly regarding the improvement of mobility and functional outcomes ${ }^{2,3}$. Modern treatment options for unstable intertrochanteric fractures include intramedullary (e.g., PFNA, Proximal femoral nail antirotation; PFN, Proximal femoral nail; IMHS, Intramedullary hip screw; TN, InterTan nail; GN, Gamma nail) and extramedullary (e.g., DHS, Dynamic hip screw; CHS, Compression hip screw; PFLCP, proximal femoral locking compression plate; AMBI, AMBI sliding screw; SHS, Sliding hip screw) fixation, both of which have received empirical support ${ }^{4}$. Initially, the extramedullary sliding screw (e.g., DHS) was considered standard in the acute management of intertrochanteric fractures, though the use of intramedullary devices gradually increased, surpassing that of extramedullary devices in $2008^{5,6}$. Several studies have suggested that intramedullary devices may be the more effective option for internal fixation of unstable intertrochanteric femoral fractures, and that extramedullary fixation should be implemented with caution due to higher complication rates and poorer functional outcomes. However, other studies have reported no significant differences in outcomes between intramedullary nail and extramedullary fixation ${ }^{7-10}$. Furthermore, most previous studies have been retrospective and/or non-specific for unstable intertrochanteric fractures, necessitating further investigation ${ }^{11-15}$. Therefore, we conducted a meta-analysis of 10 randomized controlled trials involving only patients with unstable intertrochanteric fractures in order to compare mortality rates, functional outcomes and complications between intramedullary

${ }^{1}$ Orthopaedics Department of Shandong Provincial Qianfoshan Hospital, Shandong University, Jingshi Road 16766, Jinan, Shandong, 250014, PR China. ${ }^{2}$ Community health service center of zhanhua fuyuan street, Yanhe road 453, Binzhou, Shandong, 256800, PR China. Correspondence and requests for materials should be addressed to Y.-F.S. (email: syf498054232@163.com) 


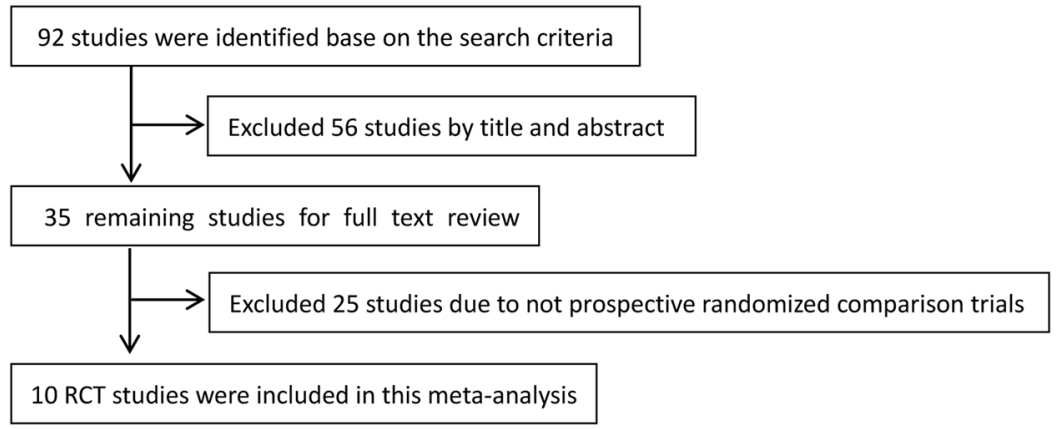

Figure 1. Flow diagram depicting the study selection procedure. A total of 10 RCTs involving 1,277 patients were included in the final meta-analysis.

\begin{tabular}{|c|c|c|c|c|c|c|c|c|c|c|}
\hline Order & Study & $\begin{array}{l}\text { Published } \\
\text { Year }\end{array}$ & Country & Method & No. & $\begin{array}{l}\text { Function } \\
\text { scoring system }\end{array}$ & P Value & Mortality & $\begin{array}{l}\text { Compli- } \\
\text { cation }\end{array}$ & $\begin{array}{l}\text { Implant- } \\
\text { related } \\
\text { complication }\end{array}$ \\
\hline 1 & Harrington, P. et al..$^{23}$ & 2002 & UK & $\begin{array}{l}\text { CHS } \\
\text { IMHS }\end{array}$ & $\begin{array}{l}52 \\
50\end{array}$ & $\begin{array}{l}\text { Living and } \\
\text { ambulatory } \\
\text { status }\end{array}$ & $>0.05$ & $\begin{array}{l}2 \\
4\end{array}$ & $\begin{array}{l}2 \\
3\end{array}$ & $\begin{array}{l}2 \\
1\end{array}$ \\
\hline 2 & Papasimos, S. et al. ${ }^{21}$ & 2005 & Greece & $\begin{array}{l}\text { DHS } \\
\text { GN, PFN }\end{array}$ & $\begin{array}{l}40 \\
80\end{array}$ & $\begin{array}{l}\text { Salvati and } \\
\text { Wilson scoring } \\
\text { system }\end{array}$ & $>0.05$ & $\begin{array}{l}1 \\
3\end{array}$ & $\begin{array}{l}10 \\
17\end{array}$ & $\begin{array}{l}2 \\
3\end{array}$ \\
\hline 3 & Barton, T. M. et al. ${ }^{17}$ & 2010 & UK & $\begin{array}{l}\text { SHS } \\
\text { GN }\end{array}$ & $\begin{array}{l}110 \\
100\end{array}$ & EuroQol 5D & $>0.05$ & $\begin{array}{l}24 \\
32\end{array}$ & $\begin{array}{l}2 \\
3\end{array}$ & $\begin{array}{l}2 \\
3\end{array}$ \\
\hline 4 & $\mathrm{Xu}, \mathrm{Y} . \mathrm{Z}$. et al. ${ }^{16}$ & 2010 & China & $\begin{array}{l}\text { DHS } \\
\text { PFNA }\end{array}$ & $\begin{array}{l}55 \\
51\end{array}$ & Mobility score & 0.0146 & $\begin{array}{l}3 \\
2\end{array}$ & $\begin{array}{l}21 \\
15\end{array}$ & $\begin{array}{l}1 \\
5\end{array}$ \\
\hline 5 & Garg, B. et al..$^{22}$ & 2011 & India & $\begin{array}{l}\text { DHS } \\
\text { PFNA }\end{array}$ & $\begin{array}{l}39 \\
42\end{array}$ & Harris hip score & $<0.05$ & $\begin{array}{l}2 \\
4\end{array}$ & $\begin{array}{l}6 \\
0\end{array}$ & $\begin{array}{l}6 \\
0\end{array}$ \\
\hline 6 & Aktselis, I. et al. ${ }^{18}$ & 2013 & Greece & $\begin{array}{l}\text { AMBI } \\
\text { GN }\end{array}$ & $\begin{array}{l}40 \\
40\end{array}$ & Barthel Index & 0.036 & $\begin{array}{l}5 \\
4\end{array}$ & $\begin{array}{l}3 \\
0\end{array}$ & $\begin{array}{l}3 \\
0\end{array}$ \\
\hline 8 & Zehir, S. et al. ${ }^{20}$ & 2015 & Turkey & $\begin{array}{l}\text { DHS } \\
\text { PFN }\end{array}$ & $\begin{array}{l}102 \\
96\end{array}$ & Walking ability & 0.14 & $\begin{array}{l}5 \\
2\end{array}$ & $\begin{array}{l}29 \\
25\end{array}$ & $\begin{array}{l}8 \\
12\end{array}$ \\
\hline 9 & Huang, S. G. et al. ${ }^{19}$ & 2015 & China & $\begin{array}{l}\text { DHS, } \\
\text { PFLCP } \\
\text { PFNA }\end{array}$ & $\begin{array}{l}60 \\
30\end{array}$ & Harris hip score & 0.06 & $\begin{array}{l}0 \\
0\end{array}$ & $\begin{array}{l}21 \\
2\end{array}$ & $\begin{array}{l}3 \\
0\end{array}$ \\
\hline 10 & Reindl, R. et al. ${ }^{25}$ & 2015 & Canada & $\begin{array}{l}\text { DHS } \\
\text { ITN, GN }\end{array}$ & $\begin{array}{l}92 \\
112\end{array}$ & $\begin{array}{l}\text { LowerEx-tremity } \\
\text { Measure (LEM) }\end{array}$ & 0.69 & $\begin{array}{l}6 \\
13\end{array}$ & $\begin{array}{l}2 \\
1\end{array}$ & $\begin{array}{l}2 \\
1\end{array}$ \\
\hline
\end{tabular}

Table 1. Main characteristics of all articles included in the meta-analysis. Abbreviations: PFNA, Proximal femoral nail antirotation; DHS, Dynamic hip screw; PFN, Proximal femoral nail; CHS, Compression hip screw; IMHS, Intramedullary hip screw; PFLCP, proximal femoral locking compression plate; AMBI, AMBI sliding screw; SHS, Sliding hip screw; ITN, InterTan nail; GN, Gamma nail.

nail and extramedullary fixation procedures, and our hypothesis was that there would be no obvious differences in mortality rates, functional outcomes and complications between the two groups.

\section{Results}

Study characteristics. We initially identified 92 studies via our search of the PubMed, Embase, Web of Science, and CBM databases. A total of 56 reports did not meet the inclusion criteria and were excluded following review of the title and abstract. Of the 35 remaining studies that underwent a full-text review, 25 were excluded because they were not randomized controlled trials. A total of 10 Randomised Controlled Ttrials (RCTs) involving 1,277 patients were included in the final meta-analysis. The study flow diagram is presented in Fig. $1^{16-25}$.

Meta -analysis results. Table 1 summarized the main characteristics of the 10 included studies. Table 2 was used to depict the Heterogeneit analysis and Forest plot results of Mortality, Function, Complications, Implant-related complications. Sensitivity analyses of mortality, complications, and implant-related complications were performed to assess the stability of the pooled effects. Our results indicated that all studies were stable (Fig. 2).

Mortality. The incidence of mortality was reported in all 10 studies. Five studies ${ }^{17,21-23,25}$ reported higher mortality for the extramedullary fixation group than the intramedullary nails group, although the opposite result was noted in three other studies ${ }^{16,18,20}$. No deaths were reported in the remaining two studies, which were excluded from this portion of analysis ${ }^{19,24}$. Chi-square, I-square, and L'Abbé analyses indicated no statistical heterogeneity $\left(\chi^{2}=4.01, \mathrm{P}=0.778, \mathrm{I}^{2}=0.00 \%\right)$ (Fig. $3 \mathrm{~A}$ ), and data pooled using a fixed-effects model indicated no statistically significant difference between the two groups (RR:0.78, 95\% CI: 0.55-1.10, $p=0.160$,) (Fig. 3B). 


\begin{tabular}{|l|l|l|l|l|l|l|}
\hline \multirow{2}{*}{ Data Results } & \multicolumn{4}{|l|}{ Heterogeneit analysis } & \multicolumn{2}{l|}{ Forest plot result } \\
\cline { 2 - 8 } & $\mathbf{x}^{2}$ & $\mathbf{P}$ & $\mathbf{I}^{\mathbf{2}}$ & $\mathbf{R R}$ & $\mathbf{9 5 \%}$ CI & P value \\
\hline Mortality & 4.01 & 0.778 & $0.00 \%$ & 0.78 & $0.55-1.10$ & 0.160 \\
\hline Function & - & - & - & - & - & 0.0028 \\
\hline Complications & 11.36 & 0.252 & $20.8 \%$, & 1.48 & $1.12-1.96$ & 0.006 \\
\hline Implant-related complications & 11.73 & 0.229 & $23.3 \%$ & 1.20, & $0.73-1.97$ & 0.475 \\
\hline
\end{tabular}

Table 2. Heterogeneit analysis and Forest plot results of Mortality, Function, Complications, Implant-related Complications.

Function. Seven primary functional scoring systems were utilized among the 10 included studies: Lower Extremity Measure (LEM), Salvati and Wilson Scoring System (SWS), Ambulatory status and Living situation, Harris Hip Score (HHS), Walking ability, EuroQol 5D, Mobility score. Barthel Index, Functional Independence Measure (FIM), Timed "Up \& Go" (TUG) test (measuring the time needed to rise from a sitting position and walk $20 \mathrm{~m}$ ), and timed two-minute walk test scores were also evaluated in some studies ${ }^{26,27}$. Exact $p$ values were reported in five of the included studies ${ }^{16,18,20,21,25}$, while the remaining studies only specified whether results were statistically significant. Functional outcomes were markedly better in the extramedullary fixation group than in the intramedullary nail group in three studies ${ }^{16,18,22}$. A P-value $<0.05$ was considered statistically significant in seven studies ${ }^{17,19-21,23-25}$. Given that there is no universal functional scoring system for measuring postoperative function and the limited number of exact $p$ values, only five studies were included in this portion of the meta-analysis. Significant differences were noted between the intramedullary nail and extramedullary treatment groups of these studies $(p=0.0028)$, although these results remain questionable, as four of the five remaining studies reported no significant difference between the two groups. Therefore, it is necessary to establish a universal system for the assessment of postoperative function in patients with unstable intertrochanteric fractures.

Complications. All 10 studies included data regarding complications, which mainly included deep vein thrombosis, wound infection, intra-operative complications, chest infection, pulmonary embolism, respiratory distress, mental disturbances, urinary tract infection, urinary retention, Femoral shaft fracture, Non-union, Cut-out, Migration of screw, Breakage of Implant were reported in the included studies and consisted mainly of femoral shaft fracture, non-union, cut-out, screw migration, implant breakage, and implant failure. The $\chi^{2}$ tests, $\mathrm{I}^{2}$ tests, and L'Abbé plots of complications indicated no obvious heterogeneity among the included studies $\left(\chi^{2}=11.36, P=0.252, I^{2}=20.8 \%\right.$, Fig. $\left.4 A\right)$, so a fixed-effects model was used for the analysis. We observed significant differences in complication rates between the two groups (RR:1.48, 95\% CI: 1.12-1.96, p = 0.006, Fig. 4B). We also carried out a subgroup analysis based on implant-related complications, such as Femoral shaft fracture, Non-union, Cut-out, Migration of screw, Breakage of Implant. No obvious statistical heterogeneity was observed among results for implant-related complications $\left(\mathrm{Chi}^{2}=11.73, \mathrm{P}=0.229, \mathrm{I}^{2}=23.3 \%\right.$, Fig. $\left.4 \mathrm{C}\right)$. Data pooled using a fixed-effects model indicated no significant difference in the incidence of implant-related complications between the two groups (RR:1.20, 95\% CI: 0.73-1.97, $\mathrm{p}=0.475$, Fig. 4D).

Publication bias. We assessed publication bias using Begg's test and Egger's test. The funnel plot for the meta-analysis of mortality for intramedullary nail versus extramedullary fixation was largely symmetric $\left(\mathrm{P}_{\text {Begg }}=0.902, \mathrm{P}_{\text {Egger }}=0.567\right.$, Fig. 5A,B $)$. Similar results were observed for complication rates $\left(\mathrm{P}_{\text {Begg }}=0.210\right.$, $\mathrm{P}_{\text {Egger }}=0.137$, Fig. 5C,D). In addition, we performed the Duval and Tweedie nonparametric "trim and fill" method of accounting for publication bias in meta-analysis, which indicated no publication bias for implant-related complications among these studies (Fig. 5E). The pooled estimate of the fixed-effects model was -0.326 (95\% CI: $-0.857-0.204$ ), while the pooled estimate of the random-effects model was -0.283 (95\% CI: $-1.061-0.496$ ).

\section{Discussion}

Unstable intertrochanteric fractures are difficult to manage ${ }^{2}$. Several fixation devices have been developed to overcome the difficulties encountered in the treatment of such fractures, including extramedullary (DHS, CHS, PFLCP, AMBI, SHS) and intramedullary (ITN, PFNA, GN) devices ${ }^{28}$. However, researchers have reported conflicting results regarding differences in mortality, functional outcomes, and complications between intramedullary nail and extramedullary fixation ${ }^{11,14,29}$. We therefore conducted a meta-analysis to determine whether evidence-based support for an optimal fixation device exists for unstable intertrochanteric fractures. In order to provide the best current evidence on the treatment of unstable intertrochanteric fractures, we included only studies that compared intramedullary nail and extramedullary devices. We identified 10 relevant randomized controlled trials and subsequently compared mortality rates, functional outcomes, and complications between patients treated with intramedullary nail and extramedullary fixation devices.

Johnell $\mathrm{O}$ concluded that hip fracture is a significant cause of morbidity and mortality worldwide ${ }^{30}$. Our study demonstrated no statistically significant difference in one-year mortality between intramedullary nail and extramedullary fixations and other research has shown that the advanced age and medical comorbidities led to a mortality rate of almost $10 \%$ within the first year after the fracture occurred ${ }^{31}$. Surgical management of unstable intertrochanteric fractures has evolved over the past few decades in a quest to improve functional outcomes in this patient population. when considering patients' postoperative function of the two kinds of fixations, a literature review by I.B. Schipper suggested both intramedullary and extramedullary fixation offer clinical advantages for unstable trochanteric femoral fractures ${ }^{4}$. Another meta-analysis recommend the intramedullary nail technique for the treatment of unstable femoral intertrochanteric fractures due to better functional outcomes and 
A

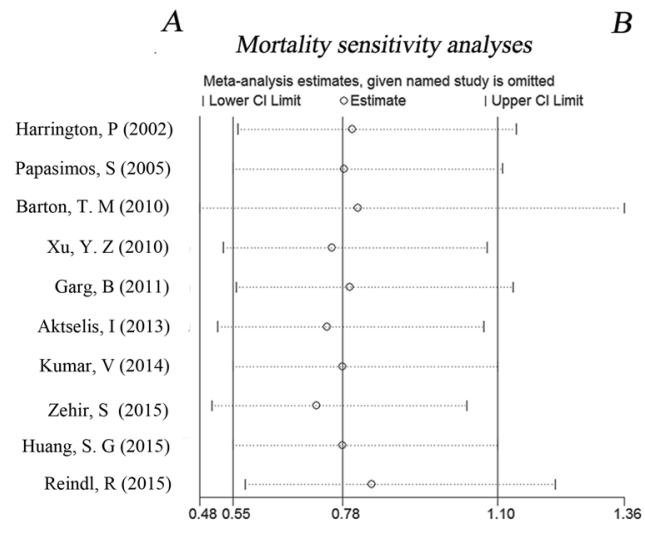

$B$

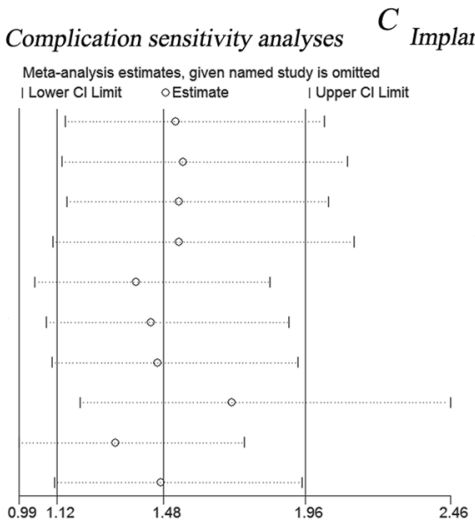

C Implant-related complication sensitivity analyses

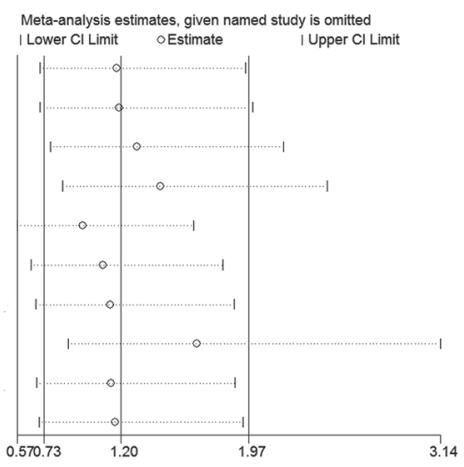

Figure 2. Sensitivity analyses of mortality, complications, and implant-related complications. The results indicated that all studies were stable.

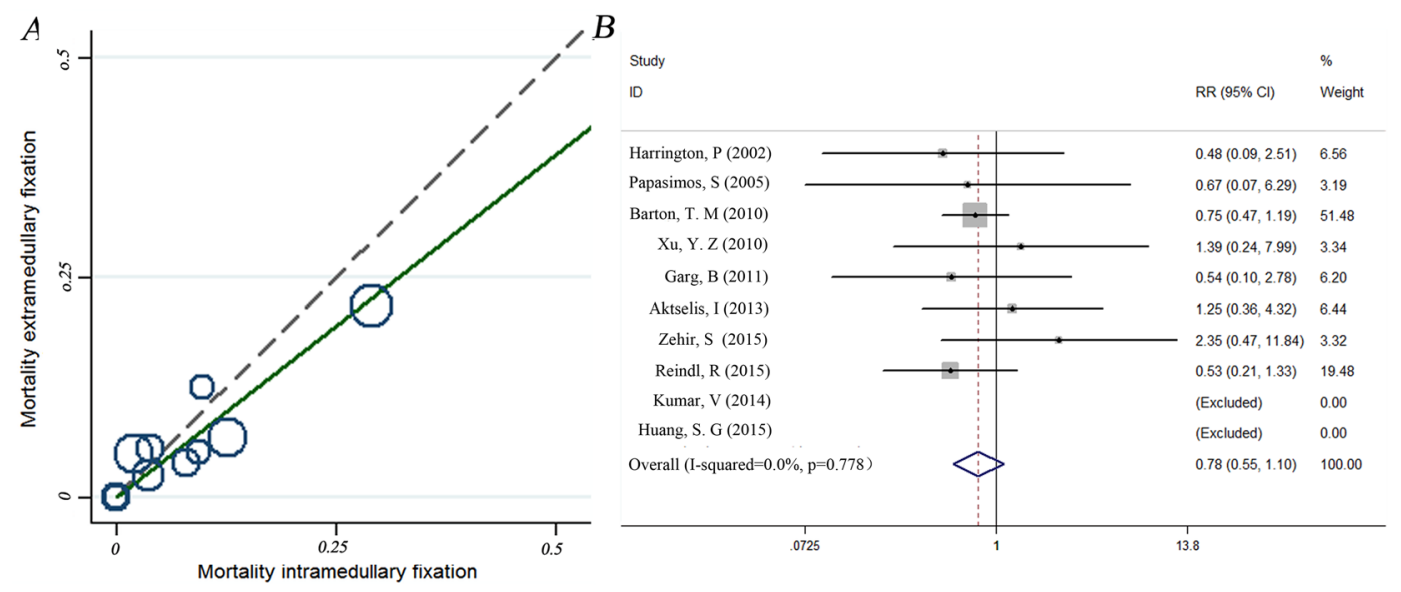

Figure 3. L'Abbé plot (A) and forest plot (B) for the meta-analysis of mortality between intramedullary nail and extramedullary fixation. L'Abbé analyses indicated no statistical heterogeneity $\left(X^{2}=4.01, \mathrm{P}=0.778, \mathrm{I} 2=0.00 \%\right)$, and data pooled using a fixed-effects model indicated no statistically significant difference between the two groups (RR:0.78, 95\% CI: $0.55-1.10, \mathrm{p}=0.160$ ).

reduced blood $\operatorname{loss}^{28}$. Our study pointed to exact $\mathrm{p}$ values from five studies indicated that functional outcomes were markedly better for intramedullary nail than extramedullary fixation $(p=0.0028)$. However, the lack of universally accepted functional scoring systems and low number of studies included in this analysis indicate that further investigation is required.

There are multiple factors that influences these two treatment options such as type of implant, type of fracture, patients age, co-mobidities, bone quality, time of treatment. Suitable implant selection according the type of fracture is an important factor to reduce the incidence of complication for unstable fracture in aged patients ${ }^{32}$. For the treatment of intertrochanteric fractures, intramedullary nail and extramedullary fixation, but each has advantages and disadvantages. On the one hand, Intramedullary fixation has multiple theoretical advantages for the treatment of unstable fracture patterns, such as biomechanical advantages, simple manipulation, small exposure, less complications, earlier mobilization. But they would be subject to the diameter of the medullary cavity and were inferior to extramedullary fixation in controlling rotational stability. Worse still, the endosteum blood supply was destroyed in the process of reaming. On the other hand, extramedullary fixation like the dynamic hip screw, whose advantage was interfragmental compression effect with a high union rate, and a minimally invasive technique was used to reduce soft tissue stripping and blood loss. But the extramedullary fixation had a higher incidence of varus collapse, medialization of the distal fragment and cut out of the femoral head screw in the treatment of unstable intertrochanteric fractures, which combined with lateral wall or posteromedial comminution, fractures with reverse obliquity pattern ${ }^{33}$. Honestly speaking, there was still no significant difference in the strength of fixation of stable and unstable infertrochanteric fractures between intramedullary nail and extramedullary fixation, although the intramedullary nail more rigid fixation ${ }^{34}$. Intertrochanteric fractures classified as unstable (AO/ASIF classification: 31-A2/31-A3), however, have a higher risk of complications and mechanical failure in comparison with stable fractures. Recent data have suggested that some unstable fracture patterns, such as reverse obliquity, and highly comminuted, could benefit from intramedullary nailing ${ }^{35}$. Comorbidities like osteoporosis may lead to technical problems during the procedure and complications sustained screw cut-out, 


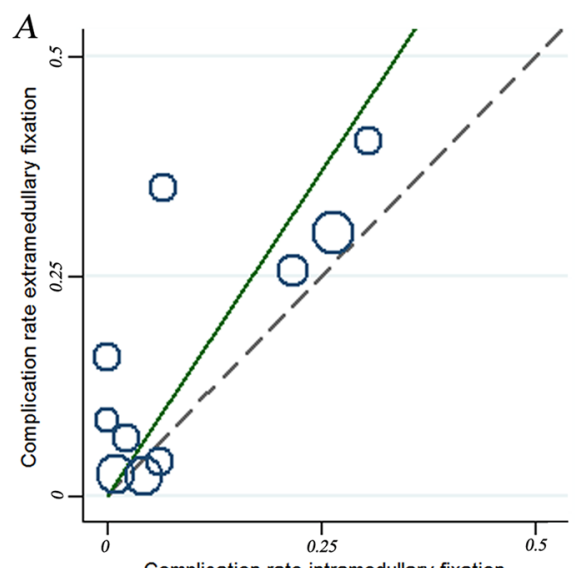

$B$

$\%$

RR (95\% Cl) Weign

Harrington, $\mathrm{P}(2002) \quad$\begin{tabular}{l|lll}
- & \\
\hline & $0.64(0.11,3.66)$ & 4.76
\end{tabular}

Papasimos, S (2005)

Barton, T. M (2010)

$\mathrm{Xu}, \mathrm{Y} . \mathrm{Z}(2010)$

Garg, B (2011)

Aktselis, I (2013)

Kumar, V (2014)

Zehir, S (2015)

Huang, S. G (2015)

Reindl, R (2015)

Overall (I-squared- $20.8 \%, \mathrm{p}=0.252$ )

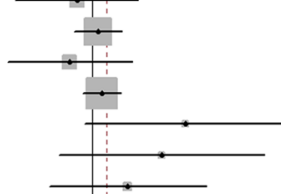

$1.18(0.60,2.32) \quad 17.64$

$0.53(0.09,3.07) \quad 5.22$

$1.32(0.77,2.25) \quad 24.04$

$14.00(0.82,240.40) \quad 0.75$

$7.19(0.39,134.39) \quad 0.77$

$2.74(0.30,25.33) \quad 1.63$

$1.12(0.71,1.77) \quad 39.52$

$5.25(1.32,20.92) \quad 4.15$

$2.10(0.19,22.68) \quad 1.52$

\begin{tabular}{l|l}
0 & 0 \\
\hline
\end{tabular}

Complication rate intramedullarv fixation

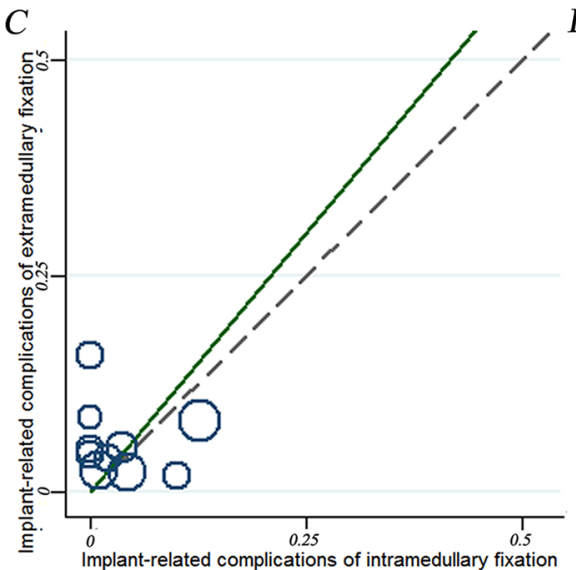

$D$

Study

$\%$

$1.80(0.17,19.19) \quad 3.92$

Harrington, P (2002)

Papasimos, S (2005)

Barton, T. M (2010)

$\mathrm{Xu}, \mathrm{Y}, \mathrm{Z}(2010)$

Garg, B (2011)

Aktselis, I (2013)

Kumar, V (2014)

Zehir, S (2015)

Huang, S. G (2015)

Reindl, R (2015)

Overall (I-squared $=23.3 \%, \mathrm{p}=0.229$ )

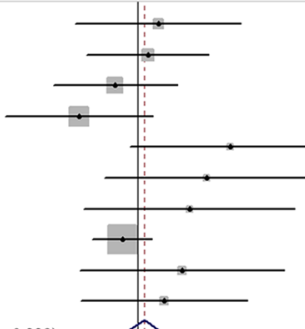

$1.33(0.23,7.65) \quad 7.44$

$0.53(0.09,3.07) \quad 12.47$

$0.19(0.02,1.56) \quad 19.16$

$14.00(0.82,240.40) \quad 1.79$

$7.19(0.39,134.39) \quad 1.83$

$4.36(0.22,88.25) \quad 1.99$

$0.65(0.28,1.51) \quad 45.35$

$3.56(0.19,66.72) \quad 2.47$

$2.15(0.20,23.23) \quad 3.59$

$20(0.73,1.97) \quad 100.00$

Figure 4. L'Abbé plot $(\mathbf{A}, \mathbf{C})$ and forest plot $(\mathbf{B}, \mathbf{D})$ for the meta-analysis of complication and implant-related complication rates between intramedullary nail and extramedullary fixation. L'Abbé plots of complications and implant-related complications indicated no obvious heterogeneity among the included studies, We observed significant differences in complication rates, but no significant difference in the incidence of implant-related complications between the two groups.

loss of reduction, delayed union, malunion or nonunion, and various deformities of the femur, Because of the biome-chanical advantage and unique design (ITN and PFNA) for osteoporosis, the intramedullary nail appears to be a reliable implant in the management of intertrochanteric fracture in elderly patients with primary osteoporosis ${ }^{36}$. Higher operative time could result in more blood loss and higher infection rate, therefore, in order to reduce operative time, we had to choose to stick with their most-familiar implant system ${ }^{37}$.

More recent studies have reported little difference in complication rates and ambiguous clinical outcomes between intramedullary nail and open reduction/internal fixation (ORIF) surgical methods, making it difficult to determine the ideal implant due to risks and benefits associated with each device ${ }^{8,38,39}$. We observed a higher incidence of complications for extramedullary fixation than for intramedullary nail, which may be due to the biomechanical advantages of intramedullary fixation ${ }^{34}$. We also carried out a subgroup analysis based on implant-related complications, such as Femoral shaft fracture, Non-union, Cut-out, Migration of screw, Breakage of Implant and so on. Nevertheless, no significant differences in implant-related complications were observed between the groups. The main reasons responsible for the implant-related complications are such iatrogenic factors as biomechanically unsuitable position, unskillful surgical technique and improper post-operative instruction for functional exercise $e^{40,41}$.

The present meta-analysis, however, is limited in that few large-scale, multi-center RCTs specified for unstable femoral intertrochanteric fractures were included. Many trials included both stable and unstable fractures were not taken into account, only 10 published studies could be used for specific analysis of results in unstable fractures. Moreover, In our research, only five studies were included in this portion of the meta-analysis to evaluate the function. This fact limits the validity considerably. A significant difference considering all included studies was not possible. Besides, many trials failed to analyse results according to fracture type, patients age, co-mobidities, bone quality and time of treatment. As a result, Future large-scale studies should therefore aim to establish a universal standard for evaluating the efficacy of both treatments in this patient population. Similarly, evidence suggesting that patients treated with intramedullary nail experience better functional outcomes remains questionable, further supporting the need for a universal tool for the assessment of postoperative function. However, more conclusive evidence suggests that intramedullary nail is associated with fewer complications than 
$A$
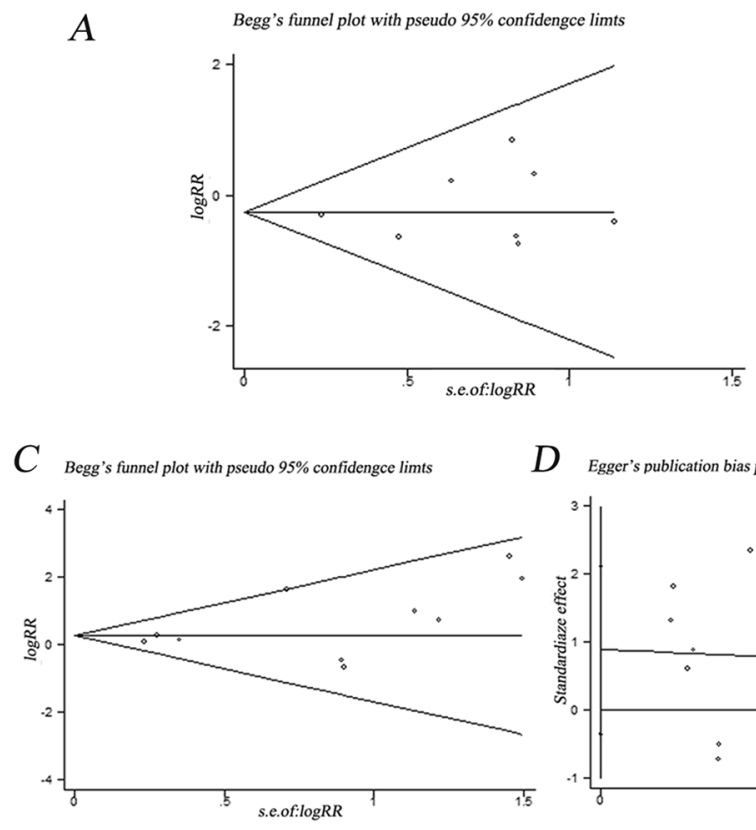

Egger's publication bias plot

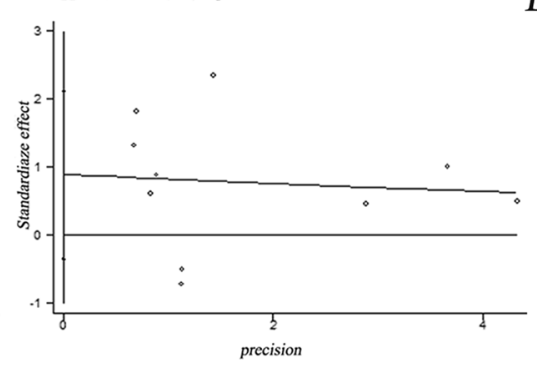

$B$

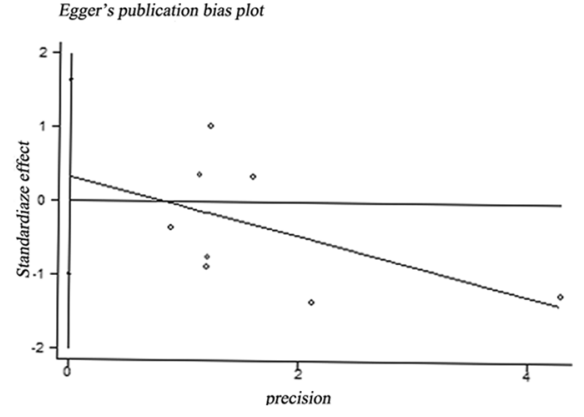

E

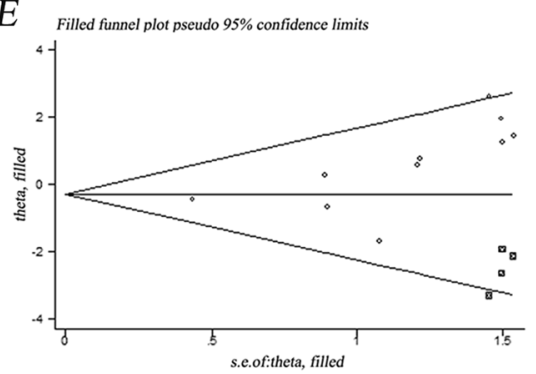

Figure 5. Funnel plot for publication bias. (A) Begg's funnel plots and Egger's test (B) of mortality. Begg's funnel plots (C) and Egger's test (D) of complications. (E) Duval and Tweedie nonparametric "trim and fill" method of accounting for publication bias for implant-related complications. There were no publication bias for mortality, complications and implant-related complications among these studies.

extramedullary fixation, Therefore, the intramedullary nail method would be more reliable and should be encouraging for unstable intertrochanteric fractures.

\section{Materials and Methods}

Search strategy. We searched PubMed, Embase, Web of Science, and CBM databases using combinations of the following keywords: "unstable intertrochanteric fractures" "intramedullary nail and extramedullary fixation", "PFNA", "PFN", "Gamma nail", "InterTan", and "DHS", "CHS", "PFLCP", randomized controlled trials" (last update on December 31, 2016). Reference lists for identified reports were also retrieved and reviewed for other potentially relevant studies. All studies were carefully evaluated for repeated data. Criteria used to define duplicate data included study period, hospital, treatment information, and any additional inclusion criteria.

Inclusion and exclusion criteria. Studies that complied with the following criteria were eligible for inclusion in this study: (1) original design targeted toward only unstable intertrochanteric fractures; (2) prospective, randomized, multi-center design; (3) comparison of intramedullary nails and extramedullary fixation; (4) publication in English. Exclusion criteria were as follows: (1) type of literature specified as a "review", "digest", "talk", "letter", "commentary", or "case report"; (2) cadaver or model-based studies; (3) duplicate or overlapping data; (4) retrospective design.

Data extraction and quality assessment. Two authors independently extracted the data from all eligible articles, and any disagreements were resolved by discussion and consensus among the authors. Information retrieved for each study included author names, year of publication, original country, methods, number of patients, functional outcomes (clinical assessment scores) and associated $p$ values, mortality, complications, implant-related complications. We also evaluated the potential for bias in all included studies. Evaluation criteria and methods followed the Cochrane Collaboration's proposal. Statistical software Stata 12.0 (StataCorp LP, College Station, TX, USA) was used to assess the risk of bias.

Statistical analysis. We evaluated differences in outcomes between intramedullary nail and extramedullary fixation by calculating the pooled relative risk (RR) and corresponding 95\% confidence intervals (CI). Heterogeneity was assessed using chi-square and I-square tests. A fixed-effects model was used when there was no significant heterogeneity among the included studies $\left(\mathrm{I}^{2} \leq 50 \%, \mathrm{P}>0.10\right)$. A random effects model was used when an obvious heterogeneity was observed among the included studies $\left(\mathrm{I}^{2}>50 \%, \mathrm{P}<0.10\right)$. L'Abbé plots also demonstrated that there was no significant heterogeneity. Begg's funnel plots and Egger's test were used to assess the possibility of publication bias. Sensitivity analyses were also performed to assess the stability of the pooled effects. We performed statistical analysis with Stata version 12. A two-tailed P value less than 0.05 was considered statistically significant ${ }^{42-44}$. 


\section{References}

1. Sidhu, A. S., Singh, A. P., Singh, A. P. \& Singh, S. Total hip replacement as primary treatment of unstable intertrochanteric fractures in elderly patients. International Orthopaedics 34, 789-792 (2010).

2. Hassankhani, E. G., Omidi-Kashani, F., Hajitaghi, H. \& Hassankhani, G. G. How to Treat the Complex Unstable Intertrochanteric Fractures in Elderly Patients? DHS or Arthroplasty. The archives of bone and joint surgery 2, 174-179 (2014).

3. Marsh, J. L. et al. Fracture and Dislocation Classification Compendium - 2007. Journal of Orthopaedic Trauma 21, S1-S6 (2007).

4. Schipper, I. B., Marti, R. K. \& van der Werken, C. Unstable trochanteric femoral fractures: extramedullary or intramedullary fixation. Review of literature. Injury 35, 142-151 (2004).

5. Schipper, I. B. Treatment of Unstable Trochanteric Fractures. The balance between man and material. (2003).

6. Anglen, J. American Board of Orthopaedic Surgery Research Committee. Nail or plate fixation of intertrochanteric hip fractures: Changing pattern of practice. A review of the American Board of Orthopaedic Surgery database. Journal of Bone \& Joint Surgery American 90, 700-707 (2008).

7. Anglen, J. O. \& Weinstein, J. N. Nail or plate fixation of intertrochanteric hip fractures: changing pattern of practice. A review of the American Board of Orthopaedic Surgery Database. The Journal of bone and joint surgery American 90, 700-707, https://doi. org/10.2106/jbjs.g.00517 (2008).

8. Bohl, D. D. et al. Extramedullary compared with intramedullary implants for intertrochanteric hip fractures: thirty-day outcomes of 4432 procedures from the ACS NSQIP database. The Journal of bone and joint surgery American 96, 1871-1877, https://doi. org/10.2106/jbjs.n.00041 (2014).

9. Shen, J., Hu, C., Yu, S., Huang, K. \& Xie, Z. A meta-analysis of percutenous compression plate versusintramedullary nail for treatment of intertrochanteric HIP fractures. International Journal of Surgery 29, 151-158 (2016).

10. Jones, H. W., Johnston, P. \& Parker, M. Are short femoral nails superior to the sliding hip screw? A meta-analysis of 24 studies involving 3,279 fractures. International Orthopaedics 30, 69-78 (2006).

11. Knobe, M., Drescher, W., Heussen, N., Sellei, R. M. \& Pape, H. C. Is helical blade nailing superior to locked minimally invasive plating in unstable pertrochanteric fractures? Clinical Orthopaedics and Related Research ${ }^{\circledR}$ 470, 2302-2312 (2012).

12. Chua, I. T., Rajamoney, G. N. \& Kwek, E. B. Cephalomedullary nail versus sliding hip screw for unstable intertrochanteric fractures in elderly patients. Journal of Orthopaedic Surgery 21, 308-312 (2013).

13. Knobe, M. et al. Unstable pertrochanteric femur fractures. Failure rate, lag screw sliding and outcome with extra- and intramedullary devices (PCCP, DHS and PFN). Zeitschrift Fur Orthopadie Und Unfallchirurgie 147, 306-313 (2009).

14. Asif, N. et al. Unstable Intertrochanteric Fracture Fixation - Is Proximal Femoral Locked Compression Plate Better Than Dynamic Hip Screw. Journal of Clinical \& Diagnostic Research 10, 9-13 (2016).

15. Li, Y. J., Li, Z. B., Yu, W. H. \& Bo, C. F. Case-control study on dynamic hip screw and proximal femoral nail anti-rotation for the treatment of unstable intertrochanteric fractures in elderly patients. Zhongguo gu shang = China journal of orthopaedics and traumatology 26, 977-980 (2013).

16. Xu, Y. Z., Geng, D. C., Mao, H. Q., Zhu, X. S. \& Yang, H. L. A comparison of the proximal femoral nail antirotation device and dynamic hip screw in the treatment of unstable pertrochanteric fracture. Journal of International Medical Research 38, $1266-1275$ (2010).

17. Barton, T. M. et al. A comparison of the long gamma nail with the sliding hip screw for the treatment of AO/OTA 31 -A2 fractures of the proximal part of the femur: a prospective randomized trial. Journal of Bone \& Joint Surgery American 92, 792-798 (2010).

18. Aktselis, I. et al. Prospective randomised controlled trial of an intramedullary nail versus a sliding hip screw for intertrochanteric fractures of the femur. International orthopaedics 38, 155-161, https://doi.org/10.1007/s00264-013-2196-7 (2014).

19. Huang, S. G. et al. Comparison of the Clinical Effectiveness of PFNA, PFLCP, and DHS in Treatment of Unstable Intertrochanteric Femoral Fracture. American Journal of Therapeutics (2015).

20. Zehir, S., Zehir, R., Zehir, S., Azboy, İ. \& Haykir, N. Proximal femoral nail antirotation against dynamic hip screw for unstable trochanteric fractures; a prospective randomized comparison. European Journal of Trauma and Emergency Surgery 41, 1-8 (2015).

21. Papasimos, S., Koutsojannis, C. M., Panagopoulos, A., Megas, P. \& Lambiris, E. A randomised comparison of AMBI, TGN and PFN for treatment of unstable trochanteric fractures. Archives of Orthopaedic and Trauma Surgery 125, 462-468 (2005).

22. Garg, B., Marimuthu, K., Kumar, V., Malhotra, R. \& Kotwal, P. P. Outcome of short proximal femoral nail antirotation and dynamic hip screw for fixation of unstable trochanteric fractures. A randomised prospective comparative trial. Journal of Electroanalytical Chemistry 580, 41-49 (2011).

23. Harrington, P., Com, O., Nihal, A., Singhania, A. K. \& Howell, F. R. Intramedullary hip screw versus sliding hip screw for unstable intertrochanteric femoral fractures in the elderly. Injury-international Journal of the Care of the Injured 33, 23-28 (2002).

24. Kumar, V. A Comparison of Intramedullary and Extramedullary Fixation Devices in Unstable Trochanteric Fractures. International Journal of Biomedical \& Advance Research 5 (2014).

25. Reindl, R., Harvey, E. J., Berry, G. K., Rahme, E. \& Canadian Orthopaedic Trauma, S. Intramedullary Versus Extramedullary Fixation for Unstable Intertrochanteric Fractures: A Prospective Randomized Controlled Trial. The Journal of bone and joint surgery American 97, 1905-1912, https://doi.org/10.2106/JBJS.N.01007 (2015).

26. Adams, C. I., Robinson, C. M., Courtbrown, C. M. \& Mcqueen, M. M. Prospective randomized controlled trial of an intramedullary nail versus dynamic screw and plate for intertrochanteric fractures of the femur. Journal of Orthopaedic Trauma 15, 394-400 (2001).

27. Rudolf, R., Harvey, E. J., Berry, G. K. \& Elham, R. Intramedullary Versus Extramedullary Fixation for Unstable Intertrochanteric Fractures: A Prospective Randomized Controlled Trial. Journal of Bone \& Joint Surgery 97, 1905-1912 (2015).

28. Li, A. B. et al. Intramedullary and extramedullary fixations for the treatment of unstable femoral intertrochanteric fractures: a metaanalysis of prospective randomized controlled trials. International Orthopaedics, 1-11 (2016).

29. Yang, J., Wang, Z. \& Qu, T. The Treatment of Unstable Femoral Intertrochanteric Fracture. Chinese Journal of Medicinal Guide (2006).

30. Johnell, O. \& Kanis, J. A. An estimate of the worldwide prevalence, mortality and disability associated with hip fracture. Osteoporosis International 15, 897 (2004).

31. Reindl, R., Harvey, E. J., Berry, G. K. \& Rahme, E. Intramedullary Versus Extramedullary Fixation for Unstable Intertrochanteric Fractures: A Prospective Randomized Controlled Trial. Journal of Bone \& Joint Surgery 97, 1905-1912 (2015).

32. Ge, X., Zhang, J. M., Lu, W. C. \& Qiu, S. Q. Selection of the internal fixation for various types of intertrochanteric fracture in aged patients and prevention for complication. China Journal of Orthopaedics \& Traumatology 22, 385 (2009).

33. Schipper, I. B., Marti, R. K. \& Chr, V. D. W. Unstable trochanteric femoral fractures: extramedullary or intramedullary fixation: Review of literature. Injury-international Journal of the Care of the Injured 35, 142-151 (2004).

34. Curtis, M. J., Jinnah, R. H., Wilson, V. \& Cunningham, B. W. Proximal femoral fractures: a biomechanical study to compare intramedullary and extramedullary fixation. Injury-international Journal of the Care of the Injured 25, 99 (1994).

35. Cech, O., Kostál, R. \& Váchal, J. Unstable pertrochanteric fractures, biomechanic, classification and therapy. Acta Chirurgiae Orthopaedicae Et Traumatologiae Cechoslovaca 67, 17-27 (2000).

36. Zhang, H. et al. INTERTAN nail versus proximal femoral nail antirotation-Asia for intertrochanteric femur fractures in elderly patients with primary osteoporosis. Journal of International Medical Research 300060517710584 (2017).

37. Schipper, I. B. et al. Treatment of unstable trochanteric fractures. Randomised comparison of the gamma nail and the proximal femoral nail. Journal of Bone \& Joint Surgery 86, 86-94 (2004). 
38. Curtis, J. R. et al. Longitudinal Trends in Use of Bone Mass Measurement Among Older Americans, 1999-2005. Journal of Bone and Mineral Research 23, 1061-1067 (2008).

39. Swart, E., Makhni, E. C., Macaulay, W., Rosenwasser, M. P. \& Bozic, K. J. Cost-effectiveness analysis of fixation options for intertrochanteric hip fractures. Journal of Bone \& Joint Surgery 96, 1612-1620 (2014).

40. Wang, P. J. et al. Selection of internal fixation and causes of post-operative complications for unstable intertrochanteric fractures. Journal of Clinical Orthopaedics 101, 77-88 (2010).

41. Zhu, J. Y. et al. Internal fixation of unstable intertrochanteric fractures and post-op erative complications in elderly patients. Chinese Journal of Orthopaedic Trauma (2005)

42. Higgins, J. P., Thompson, S. G., Deeks, J. J. \& Altman, D. G. Measuring inconsistency in meta-analyses. British Medical Journal 327, 557-560 (2003).

43. Mantel, N. \& Haenszel, W. Statistical aspects of the analysis of data from retrospective studies of disease. JNCI: Journal of the National Cancer Institute 22, 719-748 (1959).

44. Egger, M., Smith, G. D., Schneider, M. \& Minder, C. Bias in meta-analysis detected by a simple, graphical test. BMJ 315, 629-634 (1998).

\section{Acknowledgements}

We gratefully appreciate Shandong University for providing the statistical and technical assistance. This work was supported by the Medicine and health care Science Foundation of Shandong Province of China (2016WS0460) and the Natural Science Foundation of China (81702667).

\section{Author Contributions}

Yi-Feng Sun conceived the study and wrote the manuscript, Wen-Qiang Zang analyzed the data, Jian Sun generated data. All authors reviewed the manuscript.

\section{Additional Information}

Competing Interests: The authors declare that they have no competing interests.

Publisher's note: Springer Nature remains neutral with regard to jurisdictional claims in published maps and institutional affiliations.

(c) (i) Open Access This article is licensed under a Creative Commons Attribution 4.0 International License, which permits use, sharing, adaptation, distribution and reproduction in any medium or format, as long as you give appropriate credit to the original author(s) and the source, provide a link to the Creative Commons license, and indicate if changes were made. The images or other third party material in this article are included in the article's Creative Commons license, unless indicated otherwise in a credit line to the material. If material is not included in the article's Creative Commons license and your intended use is not permitted by statutory regulation or exceeds the permitted use, you will need to obtain permission directly from the copyright holder. To view a copy of this license, visit http://creativecommons.org/licenses/by/4.0/.

(C) The Author(s) 2018 